\title{
HIDRADENITE SUPURATIVA PERIANAL COMO DIAGNÓSTICO DIFERENCIAL DE DOENÇA INFLAMATÓRIA INTESTINAL FISTULIZANTE
}

\section{RELATO DE CASO}

SANTOS, Henrique Amorim ${ }^{1}$

FERREIRA, Amanda Karolyne Batista ${ }^{2}$

LEAL, Ana Carolina Cunha ${ }^{3}$

VILELA, Julia Carmo ${ }^{4}$

RORIZ, Julia Martins ${ }^{5}$

LAIA, Marcella Gonçalves de ${ }^{6}$

SANTOS, Isabella Amorim ${ }^{7}$

\footnotetext{
${ }^{1}$ Atualmente médico residente Cirurgia Geral Universidade Federal Triângulo Mineiro, médico graduado pela Faculdade de Ciências da Saúde de Barretos Dr Paulo Prata em 2018.

${ }^{2}$ Atualmente médica residente Cirurgia Geral Universidade Federal Triângulo Mineiro, médica graduada pela Universidade de Uberaba em 2018.

${ }^{3}$ Atualmente graduanda Medicina Universidade Federal do Triângulo Mineiro.

${ }^{4}$ Atualmente graduanda Medicina Universidade Federal do Triângulo Mineiro.

${ }^{5}$ Atualmente graduanda Medicina Universidade Federal do Triângulo Mineiro.

${ }^{6}$ Atualmente graduanda Medicina Universidade Federal do Triângulo Mineiro.

${ }^{7}$ Atualmente graduanda Medicina Universidade de Franca.
} 
ASSIS, Lídia Alberoni Neves de ${ }^{8}$

SILVA, Emerson Abdulmassih Wood da ${ }^{9}$

SANTOS, Henrique Amorim. Et al. Hidradenite supurativa perianal como diagnóstico diferencial de doença inflamatória intestinal fistulizante. Revista Científica Multidisciplinar Núcleo do Conhecimento. Ano 05, Ed. 08, Vol. 16, pp. 4856. Agosto de 2020. ISSN: 2448-0959, Link de acesso: https://www.nucleodoconhecimento.com.br/saude/hidradenite-supurativa

\section{RESUMO}

A hidradenite supurativa perianal é uma doença inflamatória crônica de etiologia multifatorial que possui uma prevalência de $4 \%$, acometendo principalmente indivíduos entre a segunda e terceira décadas de vida, além de ser mais frequente em mulheres. $\mathrm{O}$ acometimento de ductos das glândulas apócrinas causa lesões do tipo abscesso, nódulo, túneis ou cicatrizes. Foi discutida ainda a etiopatogenia da doença em questão e as estratégias de diagnóstico e tratamento específico. Este estudo de caso buscou evidenciar as manifestações clínicas da hidradenite supurativa e a construção do diagnóstico diferencial de doença inflamatória intestinal. Apresentamos o caso de um paciente com lesões pustulosas em região perianal há dois anos. Após

8 Atualmente médica residente Coloproctologia pela Universidade Federal do Triângulo Mineiro, Residência em Cirurgia do Trauma pelo HRTN UFMG Belo Horizonte, Residência Cirurgia Geral HRAD FHEMIG Patos de Minas-MG, Graduação médica pela Universidade Federal de Minas Gerais.

${ }^{9}$ Médico formado em 1982 pela Faculdade de Medicina do Triângulo Mineiro. Concluiu em 1984 Residência Médica em Cirurgia Geral no Hospital Escola da Universidade Federal do Triângulo Mineiro (UFTM). Trabalha na UFTM como médico no Pronto Socorro Adulto desde 1985 na área de Cirurgia Geral e atendimento Trauma. Trabalha como médico Coloproctologista no Ambulatório Maria da Glória. Mestre em Biopatologia pela Universidade de Uberaba (2014) e Doutor em Patologia pela UFTM (2018). 
exame clínico e biópsia, foi diagnosticado com quadro de hidradenite supurativa perianal, descartando a suspeita de doença inflamatória intestinal fistulizante. $\mathrm{O}$ paciente foi submetido a ressecção cirúrgica associada a sessões de câmara hiperbárica com cicatrização completa das lesões e bom prognóstico e melhora do paciente.

Palavras-chave: Hidradenite supurativa, doença de crohn, diagnóstico diferencial.

\section{INTRODUÇÃO}

A hidradenite supurativa trata-se de uma afecção inflamatória crônica que acomete ductos das glândulas sudoríparas apócrinas e mistas (SAUNTE et al., 2017 apud ZOUBOULIS et al., 2015). Possui etiologia multifatorial, relacionada à alteração hormonal, desordens metabólicas, tabagismo, além de predisposição genética, em que cerca de um terço dos pacientes relatam histórico familiar da doença (JEMEC, 2012). Estudos recentes ainda sugerem que a doença seja uma condição inflamatória sistêmica, com o envolvimento de diversas citocinas, como IL-12, IL-23, TNF-alfa, entre outras, na patogênese da doença (JEMEC, 2012; SMITH et al, 2017). Sua origem está na oclusão folicular seguida de dilatação pilo-sebácea, reação inflamatória e infecção bacteriana secundária, manifestando-se como nódulos subcutâneos eritematosos, endurecidos e dolorosos que formam abscessos com drenagem espontânea purulenta e fétida.

Quanto a prevalência da hidradenite supurativa, esta varia de 0,05 a 4,10\% (SAUNTE et al., 2017) e indivíduos entre segunda e terceira décadas de vida são os mais acometidos, com destaque para as mulheres, que, quando comparada aos homens, apresentam esta doença na proporção de 3:1 (MARTORELL et al., 2015).

O diagnóstico é essencialmente clínico, realizado a partir da morfologia da lesão de hidradenite supurativa, a qual pode ser um nódulo, abscesso, túneis ou cicatrizes; pela progressão da lesão - duas recorrências em seis meses ou persistência por três meses -, ou seja, lesões crônicas; além de sua localização. As apresentações mais frequentes são em regiões axilar, inframamária, retro auricular, inguinal e perineal 
(SAUNTE et al., 2017). Apesar de ser uma doença benigna, a hidradenite supurativa está relacionada à grande impacto biopsicossocial, em decorrência dos locais de acometimento das lesões, que podem afetar a saúde sexual e saúde mental do paciente, o qual pode evoluir com depressão e ansiedade (SHAVIT et al., 2014; JANSE et al., 2017).

Com a evolução da doença, pode ocorrer fistulização e/ou formação de fibrose, de forma que, quando acomete região perianal, temos as doenças inflamatórias supurativas perianais entre o rol de diagnósticos diferenciais. Aumenta-se o grau de suspeição de hidradenite supurativa em casos de abscessos que não respondem ao tratamento padrão com antibioticoterapia. Em casos selecionados, testes adicionais podem ajudar no diagnóstico, mas biópsias e culturas bacteriológicas são indicados apenas em casos atípicos ou refratários (JEMEC, 2012). Por se tratar de uma afecção com tendência a recorrência, o tratamento cirúrgico tem sido considerado como medida curativa com maior efetividade.

O objetivo do presente estudo é relatar o caso de paciente diagnosticado com hidradenite supurativa perianal, assim como seus respectivos sinais e sintomas, evolução e desfecho pós cirúrgico. Objetiva-se, ainda, ressaltar a importância da investigação ativa de possíveis diagnósticos diferenciais para casos como este, em que doenças inflamatórias intestinais fistulizantes, como predominantemente a doença de Crohn e a colite ulcerosa, estão no rol de hipóteses diagnósticas.

\section{DESENVOLVIMENTO}

Caso: Paciente C.B.S, sexo masculino, 41 anos, vaqueiro, casado, comparece em consulta inicial no ambulatório de Coloproctologia encaminhado da cidade de origem com queixa de múltiplas lesões de característica pustulosa, em região perianal e de nádegas bilateralmente, com aparecimento há 2 anos. Relata que por vezes há drenagem de secreção purulenta fétida espontaneamente. Associado ao quadro, relata ainda dor local, edema, prurido, calor e hiperemia. Nega alterações do padrão evacuatório, apresenta hábito intestinal com evacuações $2 x$ ao dia. Nega ainda sintomas sistêmicos associados. Nega comorbidades ou uso de medicamentos. 
Tabagista e etilista. Fez uso de antibiótico por 7 dias conforme prescrição médica sem melhora dos sintomas.

Ao exame físico: presença de inúmeras lesões supurativas em região perianal e glúteos, com drenagem de secreção amarelada com odor fétido, sinais flogísticos locais; anuscopia sem alterações. Sem alterações bioquímicas laboratoriais e sorologias negativas. Submetido a colonoscopia, exame macroscopicamente sem alterações e colhido material para biópsia que demonstrou mucosa de aspecto normal, sem alterações sugestivas de Doença Inflamatória Intestinal. Realizou ressonância magnética de pelve sendo evidenciado trajeto fistuloso de aproximadamente $6,8 \mathrm{~cm}$ comunicando parede do ânus às $07 \mathrm{~h}$, distando $3 \mathrm{~cm}$ da borda anal, com coleção localizada em subcutâneo de região da nádega à direita, com volume estimado em 30 $\mathrm{ml}$.

Diagnosticado com Hidradenite Supurativa (HS), com indicação da realização de procedimentos cirúrgicos após a tentativa da eliciação sem sucesso. Submetido a ressecção de pele e subcutâneo de região glútea, com margens amplas, preservação da musculatura esfincteriana, procedimento sem intercorrências. Material encaminhado ao anatomopatológico. Após procedimento realizou curativo assistido pela equipe da cirurgia plástica associado a sessões de câmara hiperbárica e posteriormente curativo domiciliar com hidrogel, e cicatrização completa local. O anatomopatológico da peça cirúrgica ressecada mostrou pele e subcutâneo com intensa inflamação crônica produtiva supurativa, abscessos profundos na hipoderme, fibrose cicatricial, hemossiderina, atrofia de glândulas sudoríparas e formação de cisto epidermoide - hidradenite supurativa crônica.

Discussão: A (HS), ou Acne Inversa, patologia diagnosticada no paciente deste relato de caso, é uma doença inflamatória caracterizada por lesões nódulo pustulares crônicas e recorrentes, que podem coalescer-se em abscessos dolorosos e fistulizantes na derme, com drenagem esporádica de exsudato purulento fétido com a presença ou não de sangue, sendo essas manifestações clínicas também relatadas na história clínica em questão (SMITH et al., 2017; PAULA et al., 2010). Os desenvolvimentos das lesões supurativas nesse paciente ocorreram em região 
perineal e glúteos, que juntamente com as axilas e a região inguinal, são os locais mais acometidos pela HS, justificado pela grande concentração de glândulas apócrinas e complexos pilo-sebáceos nessas regiões (SMITH et al., 2017). Alguns fatores de risco relacionam-se com a HS como distúrbios endócrinos, imunológicos e genéticos e fatores comportamentais como higiene precária, roupas ajustadas, uso de irritantes químicos como desodorantes e fármacos (MARTORELL et al., 2015). A doença está associada também a algumas comorbidades como obesidade, tabagismo e síndrome metabólica, além disso, devido a inflamação sistêmica causada pela HS, os pacientes têm uma chance maior de desenvolver doença aterosclerótica (SMITH et al., 2017). No estudo de Paula et al (2010) foi constatado uma forte associação do tabagismo com a HS, o que se observa também nesse estudo com o paciente em questão sendo tabagista.

No início da doença, é possível perceber alguns sinais como eritema, ardor, prurido e hiperidrose que avança com o aparecimento de nódulos profundos, sinais e sintomas referidos pelo paciente na anamnese da consulta inicial. Algumas complicações da HS envolvem a cronificação de fístulas e abcessos, formando placas e cordões fibróticos, cicatrizes hipertróficas e desfiguração anatômica estigmatizante (LEE et al., 2017). Em revisão, Saunte et al (2017) esclarecem que lesões iniciais tem flora bacteriana normal na pele, isso sugere que a infecção bacteriana é secundária a inflamação pré-existente no local o que explicaria o insucesso da antibioticoterapia no paciente relatado. A literatura indica ainda que, considerando os homens como subtipo mais comum, a recorrência de lesões perineais e a evolução destas apresentam as maiores taxas, de concordância com o caso (PAULA et al., 2010).

O diagnóstico precoce é essencial para prevenir complicações decorrentes da cronicidade. Entretanto, percebe-se um atraso em realizá-lo, com dados da literatura estimando uma média de 7,2 anos o que evidencia que o diagnóstico realizado no caso em questão está abaixo da média, ao passo que 2 anos de afecção ainda seja um tempo prolongado (SAUNTE et al., 2017). O diagnóstico é feito principalmente de forma clínica e muitas vezes há uma confusão com furúnculos, acne, tuberculose cutânea e Doença de Crohn, esta última que possui uma forte associação relatada 
(LEE et al., 2017). A hidradenite supurativa tem frequência aumentada em pacientes com Doença de Crohn, afetando $17 \%$ desses pacientes. A relação entre as duas patologias é sustentada por similaridades clínicas, histológicas e epidemiológicas, como tratos sinusais, inflamação granulomatosa cicatrização e início após puberdade (JEMEC, 2012).

Para o diagnóstico da HS no paciente em questão, foram contempladas as três principais características, sendo elas lesões típicas, que incluem nódulos, abscessos, tratos sinusais e cicatrizes; locais típicos, que abrangem as axilas, sulcos inframamários, virilha e períneo; e recaídas e cronicidade, em que há recorrência da patologia 2 vezes em 6 meses (LEE et al., 2017). Desse modo, percebe-se um paciente com abscessos profundos na hipoderme, com presenças de cicatrizes, lesão em local típico perianal e cronicidade de 2 anos de doença, ou seja, um indicativo forte de HS. Mesmo assim, em casos de dúvidas no diagnóstico de HS perianal, pode ser pedido uma biópsia para descartar Doença de Crohn ou outros distúrbios como foi feito, evidenciando uma mucosa normal sem indicativo de Doença Inflamatória Intestinal (LEE et al.,2017).

Para distinguir a hidradenite supurativa das demais doenças é importante considerar a aparência e os locais da lesão, a idade de início do quadro, a resposta aos antibióticos e a ausência de sepse sistêmica (MARGESSON; DANBY, 2014). Casos de furúnculos, abscessos em resposta à antibioticoterapia ou agentes infecciosos, carbúnculos, acnes e doença de Crohn cutânea devem ser excluídas das hipóteses diagnósticas para que seja feito um tratamento adequado e efetivo ao paciente (SAUNTE et al., 2017). Ademais, é válido ressaltar que a Doença de Crohn anogenital e a hidradenite supurativa podem ser associados e confundidos entre si. A doença inflamatória intestinal (DII) consiste em 2 tipos predominantes, sendo eles a doença de Crohn (DC) e a colite ulcerosa (UC). A HS compartilha manifestações clínicas comuns com a DC: são doenças crônicas, que cursam com a formação de cicatrizes, fístulas e abscessos. Ademais, essas patologias possuem semelhanças em relação à suscetibilidade genética, às características imunológicas e aos fatores de risco, a exemplo do tabagismo e da obesidade (VAN DER ZEE et al., 2010). Entretanto, é 
possível diferenciar a DC cutânea da HS devido à presença das úlceras "Knife-cut" e de fístulas que se comunicam com o trato gastrointestinal, além de frequentemente ser concomitante com a DC gastrointestinal e de não ocorrer o desenvolvimento de comedões (cravos) em sua fisiopatologia (SAUNTE et al., 2017).

O tratamento da HS é difícil e não há cura para esta patologia, mas existem intervenções eficazes disponíveis para controlar a doença e melhorar os sintomas. Os objetivos do tratamento da HS incluem prevenir novas lesões, tratar precocemente e efetivamente lesões recém-formadas, e remover nódulos existentes e tratos sinusais (LEE et al., 2017). Para a doença leve a moderada, cremes e loções antibióticas, antibióticos orais, injeções locais de esteroides, pequenos procedimentos cirúrgicos, laser e pílulas que regulam os hormônios, podem ser utilizados. Entretanto, para a forma mais grave da HS, além dos tratamentos citados, procedimentos cirúrgicos maiores e medicamentos imunossupressores são outras opções a serem consideradas. Ademais, é orientado a cessação do tabagismo, a manutenção de um peso saudável e o uso de roupas mais largas (ALIKHAN, 2016).

Mesmo que apresente altas taxas de recorrência ,o primeiro passo para a execução de um tratamento estratégico é o uso de antibioticoterapia de forma sistemática , para redução da drenagem de secreção e dores locais. Entretanto estudos apresentam outras modalidades de tratamento clínico, como terapias hormonais, fotodinâmicas, uso de imunobiológicos, radioterapia e crioterapia. A indicação dos procedimentos cirúrgicos em decorrência do diagnostico, tem sito bastante precoce, sendo considerada como a única abordagem terapêutica curativa, variando desde o desbridamento associado a agentes ablativos até a excisão de toda a área afetada com amplas margens. A reconstrução anatômica e cosmética da área inclui fechamento primário, enxertos e retalhos cutâneos e cicatrização por segunda intenção, com cuidados locais e curativos otimizados. Para a indicação dos tratamentos deve-se considerar tais fatore como as condições clínicas do paciente e o percentual da gravidade da doença com relação ao diagnóstico, sendo isto realizado de forma individualizada. 
A oxigenoterapia hiperbárica $(\mathrm{OH})$, recurso terapêutico também utilizado neste relato de caso, auxilia na cicatrização de feridas, aumenta a eficácia da antibioticoterapia e a atividade bactericida, e reduz o tempo necessário para a cura, o que garante um retorno mais breve do paciente às suas atividades e reduz a carga social da doença. $\mathrm{Na} \mathrm{OH}$, o fornecimento de oxigênio em pressões aumentadas acarreta o acréscimo da pressão parcial de oxigênio nos tecidos, o que facilita o aumento da atividade bactericida ao fornecer substrato para a formação de radicais livres de oxigênio. Além do mais, também auxilia durante o processo de cicatrização, pois o aumento desse composto estimula a formação de capilares sanguíneos, influenciando também na eficácia de alguns antibióticos (YILDIZ et al., 2016).

\section{CONSIDERAÇÕES FINAIS}

A Hidradenite Supurativa é uma doença inflamatória crônica de causa multifatorial. Reconhecer os tipos de lesão, locais mais comuns e sua etiologia se tornam necessários. Na atuação clínica da Coloproctologia, é de suma importância conhecer e identificar o diferencial do diagnóstico de hidradenite supurativa e fístulas perianais simples ou em síndromes inflamatórias fistulizantes, para a progressão do prognóstico do paciente, com relação aos tratamentos e indicação cirúrgica. $O$ diagnóstico precoce é de relevância para evitar demais complicações e comorbidades que afetam a qualidade de vida do paciente e sua saúde mental. O manejo dos pacientes deve ser feito de forma individualizada com associações de formas terapêuticas para se obter um melhor resultado. Nesse relato, a eliminação da hipótese diagnóstica através da colonoscopia e biópsia do tecido da região acometida foi essencial para o correto diagnóstico de HS, seguido da assertiva indicação de ressecção cirúrgica associada a sessões de câmara hiperbárica no pós-operatório. Tais condutas demonstraram, portanto, um excelente estudo da patologia do paciente, o que corroborou para com a efetividade do tratamento e cicatrização completa de suas lesões nódulo postulares supurativas. 


\section{REFERÊNCIAS}

ALIKHAN, A. Hidradenitis Suppurativa. JAMA Dermatology, v. 152, n. 6, p. 736, 1 jun. 2016.

JANSE, I.C. et al. Sexual health and quality of life are impaired in hidradenitis suppurativa: a multicentre cross-sectional study. British Journal Of Dermatology, [S.L.], v. 176, n. 4, p. 1042-1047, 24 fev. 2017.

JANSE, I.C. et al. Sexual health and quality of life are impaired in hidradenitis suppurativa: a multicentre cross-sectional study. British Journal Of Dermatology, [S.L.], v. 176, n. 4, p. 1042-1047, 24 fev. 2017.

JEMEC, G. B. Hidradenitis Suppurativa. New England Journal Of Medicine, [S.L.], v. 366, n. 2, p. 158-164, 12 jan. 2012. Massachusetts Medical Society.

JEMEC, G. B. E. Hidradenitis Suppurativa. New England Journal of Medicine, v. 366, n. 2, p. 158-164, 12 jan. 2012.

LEE, E. Y. et al. What is hidradenitis suppurativa? Canadian Family Physician Medecin De Famille Canadien, v. 63, n. 2, p. 114-120, fev. 2017.

LEE, E. Y. et al. What is hidradenitis suppurativa? Canadian Family Physician Medecin De Famille Canadien, v. 63, n. 2, p. 114-120, fev. 2017.

MARGESSON, L. J.; DANBY, F. W. Hidradenitis suppurativa. Best Practice \& Research Clinical Obstetrics \& Gynaecology, v. 28, n. 7, p. 1013-1027, out. 2014.

MARGESSON, L. J.; DANBY, F. W. Hidradenitis suppurativa. Best Practice \& Research Clinical Obstetrics \& Gynaecology, v. 28, n. 7, p. 1013-1027, out. 2014.

MARTORELL, A. et al. Actualización en hidradenitis supurativa (I): epidemiología, aspectos clínicos y definición de severidad de la enfermedad. Actas DermoSifiliográficas, v. 106, n. 9, p. 703-715, nov. 2015. 
PAULA, P. R. de. et al. Hidradenite supurativa crônica perianal e glútea: tratamento cirúrgico com ressecção ampla e rotação de retalho dermogorduroso. Rev bras. coloproctol., Rio de Janeiro, v. 30, n. 3, p. 326-332, set. 2010.

SAUNTE, D. M. L. et al. Hidradenitis Suppurativa. Jama, [S.L.], v. 318, n. 20, p. 2019, 28 nov. 2017.

SHAVIT, E. et al. Psychiatric comorbidities in 3207 patients with hidradenitis suppurativa. Journal Of The European Academy Of Dermatology And Venereology, [S.L.], v. 29, n. 2, p. 371-376, 9 jun. 2014.

SMITH, M. K. et al. Hidradenitis suppurativa: an update on connecting the tracts. F1000Research, v. 6, p. 1272, 28 jul. 2017.

VAN DER ZEE, H. H. et al. Hidradenitis suppurativa and inflammatory bowel disease: are they associated? Results of a pilot study. British Journal of Dermatology, v. 162, n. 1, p. 195-197, jan. 2010.

YILDIZ, H. et al. A prospective randomized controlled trial assessing the efficacy of adjunctive hyperbaric oxygen therapy in the treatment of hidradenitis suppurativa. International Journal of Dermatology, v. 55, n. 2, p. 232-237, fev. 2016.

ZOUBOULIS, C. C. et al. Hidradenitis Suppurativa/Acne Inversa: criteria for diagnosis, severity assessment, classification and disease evaluation. Dermatology, [S.L.], v. 231, n. 2, p. 184-190, jun. 2015.

Enviado: Agosto, 2020.

Aprovado: Agosto, 2020. 